\title{
HALLAZGO Y GESTACIÓN DEL YO EN EL PRIMER LIBRO Y ALBRICIA DE SOLEDAD FARIÑA
}

\author{
Ana María Riveros Soto \\ Pontificia Universidad Católica de Valparaíso, Valparaíso, Chile \\ ana.riveros@pucv.cl
}

\section{RESUMEN / ABSTRACT}

Este estudio propone una lectura centrada en la configuración del sujeto poético presente en los poemarios El Primer Libro (1985) y Albricia (1988) de Soledad Fariña (1943), bajo la comprensión de un yo en proceso continuo de gestación y nacimiento, acción que opera como mecanismo de reconstitución de una subjetividad desarticulada y extraviada en el marco de las condiciones político-culturales impuestas por la dictadura militar chilena durante las décadas de 1970 y 1980 . Por medio de la metáfora del viaje y de la búsqueda de un lenguaje nuevo, el sujeto intenta acceder a su estado primigenio en el encuentro con el yo materno y oponerse a la razón dominante, codificando y configurándose en la palabra "otra" a través del cuerpo-texto femenino. No obstante, tal proceso de gestación y hallazgo es intervenido y truncado por el impulso de la modernidad, lo que da paso a un yo malformado, escindido y descentrado, que busca constituirse en otro opuesto al logos, pugna que transforma el surgimiento del yo en un acto doloroso - un parto- efectuado desde la herida y la fisura del cuerpo, en el intento por refundar al sujeto a partir de sus fragmentos, huellas y reminiscencias.

Palabras ClaVe: sujeto, viaje, gestación, hallazgo, lenguaje.

\section{Discovery and Gestation of the SelF in El Primer Libro and Albricia BY SOLEDAD FARINA}

This study presents an interpretation of the configuration of the poetic subject in the books of poems El Primer Libro (1985) and Albricia (1988) by Soledad Fariña (1943), which understand a self in a continuous process of gestation and birth. This process serves the purpose of recomposing a disarticulated subjectivity lost in the framework of the political and cultural conditions imposed by the military dictatorship that ruled Chile in the 1970s and 1980s. By using a metaphor of a journey and searching for a new language, the subject attempts to access a primitive stage and find its maternal self in order to confront the dominant power, by codifying and configuring herself through an otherness in a feminine body-text. However, 
this process of maturation and discovery is intervened and left incomplete by the impulse of modernity, thereby creating a deformed, dissociated and off-centered self, which aims at growing opposed to logos. This conflict turns the upcoming of the new self into a painful event, like giving birth, that stems from the subject's wounded and fractured body, intending to re-establish de self from its fragments, traces and memories.

KEYWORDS: Subject, journey, gestation, discovery, language.

\section{INTRODUCCIÓN}

Los primeros dos poemarios de Soledad Fariña, correspondientes a El Primer Libro (1985) y Albricia (1988) proponen la lectura de una entidad subjetiva que deviene de un continuo y sucesivo proceso - en ambas obras-de gestación y nacimiento, de inicio y formación, instancia por medio de la cual se busca dar lugar a la reconstitución de un yo desarticulado y extraviado en el contexto de las condiciones político-culturales impuestas por el régimen militar chileno entre los años 1973 y 1990. En este marco, la crítica literaria ha enfatizado el análisis de ambos textos en relación con la metáfora del viaje efectuado por el sujeto lírico a través del cual busca este acceder a su origen, a su estado primigenio en el encuentro con el yo femenino y materno (Ortega 192-193; Olea, Prólogo 9-10; Olea, Albricia, un viaje... 35; Olea, Albricia... s/p; Merino s/p; P. Oyarzún s/p) y, en definitiva, a la posibilidad de reconocimiento de sí mismo en el estadio inaugural. De este modo, el viaje se inicia en El Primer Libro mediante la evocación a un proceso de gestación y surgimiento de un yo constitutivo y constituyente del lenguaje mismo que le da origen, esto es el lenguaje poético (Olea, Deseo y signo... 169), y propone la continuidad de este trayecto, aunque en dirección inversa, en el segundo poemario, Albricia, en tanto en esta obra el sujeto ejecuta un camino de retorno hacia el origen, al germen, al centro uterino y ancestral. En este contexto, María Teresa Adriasola alude al El Primer Libro como el "libro de la creación (...) un libro fundador del mundo" (7) mientras que Raquel Olea comprende esta obra como la representación de un "proceso de gestación y nacimiento de una palabra nueva, inédita, que emerge desde la nada, desde antes de toda escritura y todo signo (...) el rito de creación de la escritura" (Deseo y signo... 170). Por su parte, Eliana Ortega señala a propósito de Albricia: 
Soledad Fariña utiliza la aventura mítica, el viaje heroico de la tradición occidental, ella lo transforma, lo revierte, lo recrea (...) todo su viaje es una vuelta al origen-madre y todo su proceso es de re-versión (...) un descenso al origen mismo: al espacio húmedo, uterino, en que la hablante y la otra, yo y tú, se encuentran (192-193).

Bajo esta perspectiva y en el marco de una escritura para la cual la referencia precolombina y andina constituye un componente central de su poética (Bello 65-66), el viaje equivale, en otras palabras, al rito de iniciación o de pasaje mediante el cual el más joven de la tribu, después de sortear una serie de peligros en lo más profundo del bosque, logra acceder a la verdad mítica y sagrada (Eliade 9) en cuanto esta es "verdad propia, inalcanzable para la explicación racional" (Gadamer, Mito y razón 15). Dicho recorrido, que implica en Fariña nacimiento y retorno a la semilla -como versa Carpentier-, corresponde a una instancia o desplazamiento a través del cual se busca dar cuenta del proceso de conformación de una lengua distinta y fundamentalmente opuesta al discurso propio de la cultura y la razón logocéntrica, entendido este último como "dispositivo estratégico de relaciones de poder" (Foucault, Estética... 59); lo anterior, bajo el propósito de contravenir y dislocar las normas propias de la tradición literaria y artístico-cultural dominante en el contexto de la dictadura militar por medio de la creación de un lenguaje poético nuevo, un lenguaje "otro", contrario al sentido de la represión hegemónica, lo que en definitiva permite comprender el viaje como un proceso permanente de búsqueda y de encuentro, vinculado al hallazgo de otra identidad, aquella genuina y primigenia que subyace en lo más recóndito del yo y que constituye "su centro original" (Chevalier 1066), tal como permiten evocar las lecturas de Olea (Albricia, un viaje... 35 ), Ortega (193), Bellesi (s/p) y Grandón (232).

En Fariña, dicho proceso es representado a través de la metáfora del cuerpo y específicamente del cuerpo femenino, el que como texto se va codificando, construyendo y reconstruyendo por medio de la palabra y la lengua, herramienta primera mediante la cual tiene lugar la conformación de un ser primigenio y el acceso al conocimiento mítico de sí, en tanto este efectúa un recorrido sobre sí mismo -como el trazo de la escritura-, un metarrecorrido a lo largo del cual se busca dar forma al sujeto y posibilitar el encuentro con su verdadero rostro. De este modo, leemos en Albricia: 


\title{
VIAJO EN MI LENGUA
}

\author{
dos vocales \\ de arena espantosa \\ Viajo y rozan los bordes mi arenilla dormida \\ Adentro más adentro de la cavidad sonora \\ tus vocales las mías \\ en el ronco gemido \\ (...) \\ Qué sintaxis Qué paisajes que mis ojos no vieron \\ Quieren brotar de esta agua (9)
}

cierro y vuelvo hacia dentro el sol del ojo

mi ánimami alma busco (14)

Desde la crítica (Brito 187; Olea, Deseo y signo... 176; Olea, Albricia, un viaje... 35; P. Oyarzún, s/p), la noción y configuración del sujeto acontece entendida fundamentalmente como el propósito cúlmine del acto fundacional y gestacional en la escritura de Fariña y, en este marco, el encuentro del yo consigo mismo - esto es el hallazgo-no constituye otra cosa que la instancia final bajo la cual el sujeto accede al reconocimiento de su ser original a través del encuentro con lo otro: la "palabra reprimida, (...) esa "otra palabra" (Ortega 194), de naturaleza aborigen, indoamericana. En este sentido y a partir de tales búsquedas planteadas certeramente por la crítica, las que ofician como primera referencia a partir de las cuales se abordan claves fundamentales en torno a esta poesía -la noción del viaje y el retorno al origen, el carácter fundacional, la creación de una palabra poética nueva, las bases precolombinas, entre otros-, la lectura del presente estudio apunta, no obstante, hacia la conceptualización de un yo que se encuentra imposibilitado para materializar a cabalidad lo anterior, esencialmente en razón de dos propósitos centrales: por un lado, la constitución o reconstitución legítima del yo como sujeto; $y$, por otro -asociado al primero-, el acceso efectivo del yo al conocimiento respecto de sí mismo, su estadio primordial y primigenio; problemáticas cardinales que se manifiestan en Fariña mediante la comprensión de una entidad subjetiva -inquieta y movediza- que intenta permanentemente en ambos poemarios constituirse como tal, pero cuyo proceso es por el contrario intervenido, truncado, abortado, dando paso al surgimiento de un yo malformado, fragmentado y descentrado en conformidad con las restricciones 
propias de la subjetividad que impone el contexto posmoderno (Jameson 31) y las arbitrariedades dispuestas por el régimen militar ${ }^{1}$.

\section{PALABRA PRIMIGENIA Y PARTO: GESTACIÓN DE UN SUJETO MALOGRADO}

El sujeto en Fariña constituye una entidad conformada a partir de la palabra y los trazos que la producción verbal -y la lectura sucesiva- van generando simultánea y consecutivamente; es, por tanto, el cuerpo del texto, el tejido que se va formando en el acto mismo de escritura. De acuerdo con ello, ambos poemarios se comprenden como espacios mediante los cuales se busca materializar la fundación del yo, tal como lo señala Adriasola (7), en tanto el yo es el mundo, un todo en el dominio escritural del texto.

En este contexto, se reconoce en Fariña la alusión al correlato bíblico relativo al libro del Génesis y, por otro lado, a su equivalente en la literatura precolombina, el Popol Vuh y su relato inicial en torno a la creación del mundo (Adriasola 9; Ortega 193; Olea, Deseo y signo... 170; Olea, Albricia, un viaje... 35; Bello 48; Grandón 220), referencias de las cuales deriva precisamente la nominación de El Primer Libro a la opera prima de la autora, en tanto en ella tiene lugar la evocación al mito, al libro sagrado a través de cuya palabra - palabra sagrada- se posibilita la creación del mundo tal como versa el Génesis: "Dijo Dios: «Haya luz», y hubo luz" (4); relato y verbo fundacional que acontece igualmente en el mito maya-quiché, intertexto que en Fariña permite dar cuenta de la ligazón del sujeto con su origen

\footnotetext{
La necesidad de construcción de un lenguaje poético nuevo en la primera producción de Soledad Fariña, en el marco de las condiciones adversas impuestas por la dictadura militar, ha sido referida tanto por la crítica literaria (Olea, Albricia ... s/p; Ortega 191; Bellesi s/n; Bello 51), como por la autora. De este modo, Ortega apunta: “... orientación que se plantea como una indagación en el lenguaje; como una palabra que insiste en señalar condiciones de carencia, que se perciben como molestias de la indiferencia social, de las injusticias sociales, de los abusos de prácticas políticas que violan los derechos humanos. Dentro de este contexto, Albricia es poesía indagatoria" (191). Por su parte, Fariña ha señalado: "Así, las palabras, la sintaxis que teníamos guardadas quizá desde cuándo, no coincidían con la realidad brutal que vivíamos. Cómo nombrar lo que pasaba. De ahí el silencio y la mudez, las contorsiones de la escritura para expresar lo que sucedía” (Cit. en Barraza Riso s/p).
} 
primigenio, de índole andino, aborigen y latinoamericano (Ortega 193, Bello 48-49, Grandón 218-219):

Entonces vino la Palabra; vino aquí de los Dominadores, de los Poderosos del Cielo, en las tinieblas, en la noche, fue dicha por los Dominadores, los Poderosos del Cielo; hablaron; entonces celebraron consejo, entonces pensaron; se comprendieron, unieron sus palabras, sus sabidurías. Entonces se mostraron, meditaron, en el momento del alba; decidieron (construir) al hombre (...) "Tierra", dijeron, y en seguida nació (Popol-Vuh 13).

En El Primer Libro, la palabra fundacional es referida por los colores, el "amarillo oscuro de la tierra" (9) y de la arcilla, el terracota, el ocre, tonos propios de la tierra y del polvo con los cuales se da vida al hombre en el correlato bíblico y es posible en Fariña "pintar el primer libro" (9), en medio del vacío que precede a la creación del mundo: "Todo tranquilo, inmóvil" (9), y la quietud silente bajo la cual predomina la ausencia de todo sonido: "en suspenso, todo tranquilo, todo inmóvil, todo apacible, todo silencioso, todo vacío, en el cielo, en la tierra" (Popol-Vuh 12). La palabra, por consiguiente, es la entidad que quebranta, irrumpe y transgrede el silencio y la ausencia original. En Fariña, no obstante, aquel signo es a la vez una pre-palabra, el estadio previo al orden lingüístico, la palabra inicial, aquello pre-nominal que solo puede ser nombrado desde el plano de lo sublime, en los términos de Kristeva (Poder... 20) ${ }^{2}$. En El Primer Libro la palabra es el color -el color y la tierra- en tanto esta, como herramienta de escritura primigenia, antecede al uso del sistema escritural verbo-simbólico en las primeras edades del hombre y constituye, por ende, un único lenguaje o forma de expresión

\footnotetext{
A propósito de la figura de la madre mítica en la poesía de Fariña, Grandón alude a la pérdida de una 'lengua de intuición', referida por Mistral, propia de la subjetividad femenina, a causa de la represión logocéntrica: "Viene al caso entender esta hermosa comparación como metáfora de la comunicación materna preedípica, a la que se refiere Julia Kristeva al estudiar lo imaginario y lo simbólico; especialmente, sus referencias a una semiótica preverbal y presimbólica, reprimida por el logos y el lenguaje (lo simbólico) (Kristeva 1981), que parece coincidir plenamente con el planteamiento de Mistral recién citado. En efecto, Kristeva otorga especial significación a lo preedípico y lo maternal en la constitución de la subjetividad 'femenil' (para usar un neologismo mistraliano), ya que el lugar del lenguaje poético -según la teórica-se relaciona con el retorno de lo reprimido, esto es, del 'orden de lo preedípico'". (Grandón 218).
} 
pre-lingüística, creadora de mundos pictóricos regidos también por las reglas de la mímesis, "a imagen y semejanza" de Dios, como versa el Génesis (6), a imagen y semejanza del mundo circundante. El signo de escritura -la tierra, el color, el signo verbo-pictórico-, en tanto pre-palabra y lenguaje a su vez, palabra mítica, iniciática, constituye entonces el sistema simbólico a través del cual se le otorga vida al sujeto: es la palabra sagrada o el aliento que permite al sujeto poético emerger y tomar forma al tiempo que se dice, traza o esboza a sí mismo, en comunión con sus orígenes y en pos del retorno a los tiempos inmemoriales. Tal acontecimiento solo puede manifestarse en tanto consiste este en un acto sacro, basado en el contacto de la entidad subjetiva con su propio yo, con su propio cuerpo-texto en el estadio inicial, de modo previo a la palabra articulada:

untar los dedos los brazos ya estás abierto
páginas blancas abiertas no hay recorrido previo
tratar de hendir los dedos (El Primer Libro 9)

guiña el ojo tornasoles azules intensos

nunca vistos (El Primer Libro 13)

El sujeto conformado a través del aparato simbólico que constituye el lenguaje mítico o la palabra primera, consiste, no obstante, en una entidad descentrada, ajena a la institucionalidad logocéntrica y hegemónica, propia de la cultura y del sistema totalitario. El sujeto, por tanto, a quien se le busca dar forma, moldear en barro o arcilla cual sujeto adánico -"Doblado el torso la cuchilla cae / balbucea la grupa / impregna la saliva a la arcillosa / la amasa con los dedos / la mueca la reclama para sus madialunas" (El Primer Libro 13)-, intenta durante este proceso constituirse en otro, en un otro distinto, opuesto al contexto dominante, el que, cual choroyes, constituye un "registro de interferencias" (Olea, Deseo y signo... 171) que condiciona y aniquila al yo. Desde este lineamiento, la emergencia del sujeto constituye una permanente pugna entre la entidad que se gesta y busca nacer-de orden mítica y primigenia- y el entorno que lo reprime, trunca y subyuga, motivo por el cual el acto de creación y nacimiento en Fariña se vuelve en esencia un evento doloroso, un parto, el que se realiza más bien desde la herida, desde la fisura del cuerpo a partir de los vestigios y restos que del mismo van quedando. Es, por tanto, la evocación al acto inaugural, el mito de la creación 
a través del cual vuelven a surgir las marcas de un sufrimiento inmemorial ${ }^{3}$ y mediante las que se intenta, no obstante, refundar al yo en virtud de las reminiscencias, huellas y deseos, aquellos que de él han logrado pervivir: "El barro cuartea / nuestros lomos / sugiere estrías caminos secos/ arbustos espinosos de ramaje amargo" (Albricia 23); "La herida se abre impregnando / el pelaje (...) / se alargan las heridas / tentáculos de luz / hendiendo sus cuchillas / en el iris brillante" (Albricia 26-27). Asimismo, se evidencian en El Primer Libro los signos propios de la opresión y el desgarro que truncan el acto de nacimiento:

- Ha caído la nube gris sobre mi vuelo: eran granizos era hielo el que quebró mis alas (9)

Muge la tierra el ocre el terracota el gris el negro abrir la axila, hay una herida inmensa volcán reteniendo los aullidos (11)

(abrir la zanja roja afilar el cuchillo hendir abrir hasta perder la empuñadura) (13)

(...), pero hay un musgo adherido hay una maraña tupida que estorba detiene el deslizar (15)

El proceso de gestación y nacimiento se constituye, por consiguiente, en una "gesta", una batalla "épica" entre la entidad germinada y el sistema totalitario, impuesto por las circunstancias socio-históricas de la época. La acción misma

3 En Historias de las creencias y de las ideas religiosas, Eliade distingue cuatro tipos de mitos cosmogónicos. El tercero de ellos basa el relato sobre el origen del mundo en el motivo de la división o separación de la unidad primordial, respecto de la cual el autor reconoce tres variantes: "a) separación del cielo y la tierra, es decir, de los progenitores del mundo; b) separación de una masa amorfa original, el «caos»; c) la división en dos de un huevo cosmogónico" (95) (la cursiva es de Eliade). Precisamente, en el marco de la lectura que proponemos en torno a la poesía de Fariña, esta tercera modalidad y, particularmente, sus dos últimas variantes, se condicen con la concepción de un sujeto malformado y truncado, producto del parto desgarrador que implica su origen y emergencia en el contexto hegemónico nacional. 
del nacimiento, del parto, mediante la cual la gestación alcanza su estadio culminar y da cuenta de la conformación acabada -bajo supuesto- de un yo que sale a la luz, constituye la afrenta máxima ante la razón hegemónica, una acción temeraria y, a su vez, reprobatoria por la que el mismo yo debe ser desarticulado. De este modo, la primera parte de El Primer Libro denominada "donde volcarse en este paisaje" (8), en la cual ha tenido lugar el proceso de gestación del sujeto, concluye en su última estrofa con el instante mismo -acometido y forzoso- de nacimiento o surgimiento del sujeto en medio de un dominio - paisaje- eminentemente arbitrario:

rojo a la llama blanca, mugidos subterráneos
en esa oscuridad: tomar el gran pincel
afilar el cuchillo perder la empuñadura
hendir abrir hasta perder
no hay recorrido previo
había que pintar el primer libro
pero cuál pintar cuál primer (19)

El sujeto que emerge a partir de esta pugna y de la hendidura que implica es, en consecuencia, una entidad maltrecha, trunca y malformada, incluso informe, un sujeto a medias que no alcanza a constituirse como tal, a conformarse en entidad íntegra y acabada, en tanto su identidad le ha sido denegada y contradicha durante el proceso del parto, sometida por ende a condiciones de "desubjetivización" (Oyarzún, Teoría Crítica ... 36). De esta forma, los versos que inauguran la segunda sección del poemario, denominada "bandada de alas verdes" (21), inmediatamente consecutivos al nacimiento y emergencia de un yo trunco, malogrado, dan cuenta de los despojos que quedan de la entidad recién parida, a causa del entorno que lo recibe y aprisiona, inhibiendo todo su despliegue y expresión: “¿Cómo desde este nivel, ha de procurarse sujeto?”, interroga precisamente Lacan (Seminario... 222) a propósito del degarro y la escisión psicoanálitica que implica el parto -en cuanto trance- en función de la huella etimológica que liga a la nociones de parir y separación. 


\section{LA LENGUA COMO MORDAZA. APARICIÓN Y DESAPARICIÓN DEL YO}

La situación de represión a la que es sometido el sujeto desde el instante del parto -y anterior- opera, no obstante, mediante la misma materia que lo moldea y le otorga vida durante el proceso de gestación, en los albores del tiempo, esto es la lengua, el sistema verbo-simbólico, la palabra. Bajo esta línea, la palabra mítica -o primera palabra- en base a la cual se configura el sujeto, se aleja y se acerca, se entrelaza y confunde con la misma materia articulada que posibilita y reprime a la vez la aparición del yo. La lengua constituye entonces una entidad dual: desaparece para hacer emerger el conocimiento cifrado propio del mito y, al mismo tiempo, aparece para dar forma a un sujeto que se gesta a través de la escritura y la palabra. A partir de tal corporeidad -el cuerpo del texto-, la lengua se yergue como el instrumento propio de la cultura y el sistema opresor, en tanto en la materia del lenguaje residen efectivamente las formas de poder (Gadamer, Verdad... 199) por medio del cual se reprime, reduce y disecciona al sujeto:

(la lengua)

ASFALTADA

NO MAS

NO MAS melaza negra

caliente

le horada al cerebro la excavadora

(...)

Y EN QUE LA LENGUA

asfaltada ligosa tararea

sus últimos gorjeos

manto de plumas verde-choroy nadando en la laguna ahí

las fauces de los perros

lo habían empujado

al límite

a las orillas

a los bordes

(El Primer Libro 23) 
Brito comprende, precisamente, la escritura de Fariña como un intento por "doblar la línea que la cultura la obliga a tomar" (183) a través de la sintaxis y de las convenciones establecidas por el aparato verbo-simbólico, las que ofician a su vez como representantes, en el contexto chileno, de una tradición literaria esencialmente patriarcal. Desde este punto de vista, las acciones de pintar y colorear constituyen formas que intentan dar cuenta de la necesidad de otro lenguaje, de otros signos en los que pueda tener lugar la expresión poética, distintos al uso convencional de la retórica y de la lengua, y con los que sea posible, en efecto, "construir otra textualidad", como refiere Olea (Prólogo... 10). El lenguaje constituye, en consecuencia, el molde, por una parte, a través del cual se oprime y subyuga al sujeto desde su gestación, en el tiempo anterior, durante y posterior al parto; esto es la horma o matriz que limita y restringe al yo desde su formación en el útero materno, el significante del cual el sujeto poético intenta desasirse: "ataduras profundas" (12), "corteza terrosa" (17), "costra, envoltorio rugoso" (27) en El Primer Libro; "cáscara porosa" (10) en Albricia.

En esta misma línea, Kristeva concibe el lenguaje como un dispositivo de represión del sujeto poético, en tanto este intenta escapar de las marcas del yo trascendental representado por medio del hablante lingüístico, este último entendido como entidad portadora de la conciencia tética o judicativa, correspondiente al ego cartesiano (El tema... 258). De este modo, al interior del discurso literario y a diferencia de otros tipos de lenguaje no artísticos, el sujeto poético emerge en la naturaleza del entramado verbal poniendo en tela de juicio al sujeto parlante del lenguaje convencional y su respectiva conciencia tética (250). El yo poético, en su condición de entidad fallida, carente y descentrada, aparece y desaparece en el texto por medio de la figura del sujeto hablante, generando la desarticulación de este último como ego trascendental husserliano.

Kristeva recoge, en este sentido, los planteamientos del psicoanálisis freudiano, bajo el cual se comprende al sujeto como una entidad en conflicto y escindida, producto de la dialéctica entre energía pulsional ${ }^{4}$ y lenguaje a partir

\footnotetext{
Kristeva coloca énfasis a su vez en el carácter materno de la pulsión -en base a los presupuestos freudianos- como elemento constitutivo del sujeto y lenguaje poético, el que se encuentra en constante situación de represión, producto del orden simbólico: "Sólo al precio de la represión de la pulsión y de la relación continua con la madre, se constituye el lenguaje como función simbólica. En cambio, será el precio de una reactivación de lo reprimido pulsional, materno, como se sostendrá el sujeto del lenguaje poético, para quien
} 
de la cual tiene lugar la represión y negación del mismo por causa del orden simbólico, dado por el mismo lenguaje y la cultura (262-263). Para Freud, el sujeto o fragmento subjetivo tiende de modo natural hacia lo pulsional, hacia el flujo libre de esta energía; "sujeto de la pulsión y del inconsciente", en palabras de Oyarzún (Teoría Crítica... 32), el que intenta manifestarse en su encuentro o diálogo permanente con su alter ego, el "sujeto del lenguaje y la cultura", entidad esta última que actúa en conformidad con los parámetros establecidos por el orden simbólico, a diferencia del yo pulsional.

Entre ambos polos, simbólico y pulsional, fluye entonces el yo como entidad dual, lo que se reconoce en Fariña mediante la materia que constituye al propio sujeto poético, el lenguaje, en cuyo seno tiene lugar la permanente pugna entre ambas entidades: primigenia y mítica, por un lado; cultural y trascendental, por otro. En ambos poemarios, dicha tensión permanente se hace manifiesta en función del sujeto que intenta emerger y emanciparse de las trabas dispuestas por la hegemonía: "Intento abrir al ritmo de mi abdomen / un hueco a la palabra Se encabritan las olas / de mi cabeza / Aúllo Aúlla / el celador pliegue / de mi memoria" (Albricia 10).

De la convergencia de ambos registros, simbólico-cultural y pulsional, surge en Fariña, un excedente indeterminado, "ese 'otro' que somos" (Paz 137), una entidad fantasmagórica, informe y huidiza que se diluye en las tramas de la lengua, en tanto la estructura del lenguaje inhibe permanentemente el flujo de deseo y la pulsión del yo fragmentario. El sujeto es entonces concebido como una entidad bisagra, carácter que determina en rigor todo su recorrido, en función del intento permanente e imposible por emerger y salir a la luz libre de obstáculos, proceso cuyo resultado es, en consecuencia, el de un sujeto trunco, inconcluso, malogrado:

$\begin{array}{ll}\text { Falfa } & \text { mi suave } \\ & \text { la escama cae } \\ & \text { trepa la larva } \\ & \text { el rostro el paño la marga huesa }\end{array}$

\footnotetext{
la palabra nunca es exclusivamente signo. Si es la prohibición del incesto lo que constituye a su vez al lenguaje como código de comunicación (...), el lenguaje poético sería, por su sujeto, equivalente a un incesto: es en la economía misma de la significación donde el sujeto se apodera de ese territorio arcaico, pulsional y materno, con lo cual impide a la vez que la palabra se convierta simplemente en signo y la madre en un objeto como los otros, prohibido" (El tema... 263).
} 
- me dice

$(\ldots)$

DOBLA

HABLA

- le digo

( se dobla )

HABLA (El Primer Libro

31 y 33$)$

SOY LA SEMILLA OSCURA APENAS DELINEADA

(Albricia 33)

Lacan, por su parte, acuña el concepto de "mordaza" (Escritos I 260) para referirse al lenguaje, en tanto este es concebido como la cadena de significantes en la que el inconsciente -el sujeto y su deseo- se encuentra reprimido, oculto. Desde esta perspectiva, el lenguaje constituye la dimensión mediante la cual se aprisiona y encubre al yo, pero a su vez es la única vía que permite que el deseo pulsional puede asomarse, manifestarse; en consecuencia, solo es posible articular parte del deseo y del "sujeto del deseo" por medio del "desfiladero de la palabra" (Cit. en Dor 132): la articulación significante a través de la cual surge y fluye el inconsciente (132).

La teoría lacaniana postula, en este sentido, la concepción de un sujeto escindido y heterogéneo a quien solo es posible aprehender parcialmente por medio de su misma materia de represión, asociando de este modo la energía pulsional al lenguaje, pues a través de la respectiva cadena de significantes el sujeto fluye haciendo emerger la figura del inconsciente reprimido, mediante una lengua "otra" que, en definitiva, es él mismo, quien acontece entonces como entidad carente, fallida, desmembrada. El lenguaje, dominio en el que tiene lugar el advenimiento del inconsciente, constituye una entidad paradójica que reprime, encubre y devela a la vez algunos atisbos propios de la subjetividad que en ella se representa. De este modo, el inconsciente debe reconocerse necesariamente en la estructura de lenguaje (Lacan, Seminario... 211), puesto que su búsqueda o rastreo solo puede plantearse desde la materia lingüística, único medio que posibilita su vislumbre y aparición: "no hay más Sujeto que el ser hablante (el parlêtre)" (Dor 118).

En Fariña, precisamente, el sujeto no tiene posibilidad de constituirse como tal fuera de los dominios de la lengua. Por una parte, el lenguaje opera como "corteza", "membrana", en cuanto impide la emergencia y flujo directo del yo 
-"mi rostro carcomido por lenguas" (Albricia 14)-; sin embargo, por otra, es también la única arcilla capaz de dar forma al sujeto, a la vez que lo constriñe y subyuga permanentemente. De este modo, en Fariña el verbo es "lengua bífida" (El Primer Libro 27), puesto que en su propia materia significante tiene lugar la división del yo: como existencia reprimida y como entidad que busca alcanzar consistencia por medio de la palabra, hecho que no puede cumplirse cabalmente en tanto el yo que se yergue no es más que una figura trunca, informe, inacabada. En Lacan, el deseo del sujeto, su inconsciente, solo puede acontecer a través de la representación simbólica, fenómeno que da cuenta del carácter dual del lenguaje, en cuanto es este materia represiva y portadora, a la vez, del flujo pulsional: "El lenguaje es la condición del inconsciente (...) El inconsciente es la implicación lógica del lenguaje: en efecto, no hay inconsciente sin lenguaje" (Cit. en Dor 118). En Fariña, por consiguiente, es posible reconocer el intento persistente y vano a la vez de emancipación por parte del sujeto del inconsciente, en razón del deseo que fluye permanentemente con el fin de alcanzar y recuperar el estadio primigenio, en el encuentro del yo consigo mismo y su fuente original:

también abre los poros las poras

las esporas tiñe las labias

FUCSIAS

ROJAS

BERMELLONAS

terciopela

rancia

abierta

dorada

(...)

ALFA

Alfalfa olorosa

brota

enjugo el rostro

enjugo el paño (PL 21 y 31$)$

Cada salto una albricia estremeciendo

el Anca (Albricia 26) 
La lengua, no obstante, guarda en sí misma la imposibilidad de tal proceso, puesto que en su misma materia significante se genera la escisión del sujeto en virtud del inconsciente que lo constituye, lo que corresponde en definitiva a otro lenguaje:

El orden significante es, precisamente el que hace que el sujeto llegue a su estructura de división. Esto equivale a decir que el sujeto está dividido por el orden mismo del lenguaje (...) el orden significante es el que causa al sujeto, estructurándolo en un proceso de división que produce el advenimiento del inconsciente (Dor 115 y 118).

Tal escisión da cuenta, en consecuencia, del conflicto permanente sobre el cual se funda la conformación del sujeto en tanto el verbo constituye, en rigor, el lugar de su ausencia, su desaparición, dado que la naturaleza de su materia es meramente simbólica, un hecho de representación. De este modo, el sujeto representado en la cadena significante desaparece como tal al momento en que aparece como metáfora, como símbolo de una entidad en sí misma ausente. El símbolo sustituye al yo, lo desplaza, haciendo uso de un lugar en el que predomina el vacío por causa de su desaparición: "el sujeto sólo figura en su propio discurso a costa de esta misma escisión: desaparece como sujeto y sólo se encontrará representado bajo la forma de un símbolo" (Dor 122). Es así como en Fariña el sujeto adquiere, en definitiva, un sino trágico, puesto que su imposibilidad está determinada por su propia naturaleza fundada en el lenguaje, en tanto el único medio para acceder a él lo constituye finalmente su ausencia y su transformación -tergiversación- en otro, en un otro igualmente escindido y descentrado.

\section{TRADICIÓN POÉTICA, DUALIDAD Y TRANSGRESIÓN EN EL YO MATERNO}

En Fariña, el primer objeto de la otredad al cual recurre el sujeto es la figura de la madre, en su intento por retornar al espacio uterino a fin de reencontrarse con su identidad primera. La madre, la matriz, es entonces aquel "otro" con quien el sujeto desea materializar el encuentro, en oposición al orden logocéntrico contra el cual este se enfrenta; ella constituye, por ende, la pre-palabra o palabra original a partir de la cual se busca dar lugar a la reconstitución del yo. Sujeto y figura materna, yo y otro, matriz y gestación son todos, por tanto, rostros de una misma entidad que en sí misma constituye 
el objeto de la permanente búsqueda y el hallazgo, proceso en el que madre e hija confluyen, tal como propone Ortega:

Para establecer plenamente la relación entre palabra-madre y palabrahija, se hace necesario encontrar (como en el juego infantil), la palabra que nombra el poemario, la albricia (...) Su poemario Albricia es el hallazgo de la palabra reprimida, de esa "otra palabra" que nos ofrenda a nosotros (193 y 194).

En Fariña, el encuentro entre madre-hija, madre-sujeto, nos remite a la albricia, término cuyo primer antecedente encontramos en la obra Tala (1938) de Gabriela Mistral y bajo el cual se evocan sentidos asociados a las nociones de hallazgo, encuentro y revelación. En Fariña, el concepto conlleva a su vez la idea de encuentro del sujeto consigo mismo y con su propio origen -origen poético-, hecho que posibilita el acceso a su verdad sagrada, genuina y primordial. De este modo, tanto en El Primer Libro como en Albricia tiene lugar un proceso de búsqueda y de exploración que desea culminar en esta albricia, en el reencuentro del sujeto con su verdadero rostro. Para Mistral, la albricia constituye a su vez un vocablo asociado a los tiempos de la infancia, en la evocación de un juego de la niñez en el que se reproduce la búsqueda incansable y la admiración ante el hallazgo de un tesoro oculto y añorado. La exclamación "albricia" -en singular destaca el texto mistraliano-enunciada por las compañeras de juego, da cuenta entonces de este hallazgo 5 , del descubrimiento asombroso y el encuentro con "lo otro" al fin materializado:

5 El nombre "Albricia" constituyó igualmente un hallazgo que surge a partir de las lecturas que realizaron los poetas Juan Luis Martínez y Cecilia Vicuña del manuscrito de la obra. De este modo, en una entrevista audiovisual, Soledad Fariña relata: "Cuando yo tuve Albricia, le dije 'Juan Luis, y ¿tú me harías el honor de prestarme el sello Archivo para este libro?'. Pero le di el manuscrito, obviamente. 'Ya -me dijo- lo voy a leer'. (...) Y resulta que aconteció un suceso que fue la muerte de Enrique Lihn (...) Y yo me acuerdo que ahí, a la salida del Parque del Recuerdo estaba Juan Luis y nos fuimos conversando y me dijo 'Sí, Soledad -me dijo- edítalo, usa el sello Archivo. Pero ¿cómo se llama el libro?’ Entonces, yo le digo 'Es una palabra con a. Al alba, del alba...' 'No, no, no -me dijo-. El nombre tiene que estar adentro del libro, búscaselo’ (...) Y estaba la Cecilia Vicuña también, y le digo 'Cecilia, mira lo que me ha pasado, que Juan Luis me dice que tengo que buscar el nombre adentro. ¿Tú me podrías ayudar?'. Y le pasé el manuscrito. Y la Cecilia me llama en la tarde y me dice 'El nombre es Albricia' (Fariña, Sabio). Registro audiovisual alojado en el sitio http://juanluismartinez.cl/jlm/sobre-la-obra/entrevistas/. 
Albricia mía: En el juego de las Albricias que yo jugaba en mis niñeces del valle de Elqui, sea porque los chilenos nos evaporamos la s final, sea porque las albricias eran siempre cosa en singular -un objeto escondido que se buscaba- la palabra se volvía una especie de sustantivo colectivo. Tengo aún en el oído los gritos de las buscadoras y nunca he dicho la preciosa palabra sino como la oí entonces a mis camaradas de juego. (...) El sentido de la palabra en la tierra mía es de suerte, hallazgo o regalo. Yo corrí tras la albricia en mi valle de Elqui, gritándola y viéndola en unidad (Mistral 279).

En Mistral, el término acontece revestido de aquella sonoridad mágica asociada al llamado, el que se efectúa por medio de la palabra, la evocación que permite en los relatos infantiles y maravillosos acceder a otro mundo, en el encuentro de aquella otra realidad que nos remite a nuestro propio origen, en el contexto del mito ${ }^{6}$. De este modo, acontece la albricia como palabra transformadora, en tanto palabra poética, reveladora de una verdad mítica, sagrada, relativa al estadio primordial: "evocación, resurrección y recreación de algo que está en el origen de los tiempos y en el fondo de cada hombre (...), y que siendo de todos es también único y singular" (Paz 66). En Fariña, la palabra poética es precisamente la herramienta mediante la cual se ejecuta la transformación, a través del proceso de gestación y de viaje de retorno a la semilla que emprende el sujeto en la convergencia con el vientre materno, tal como se expresa en su segundo poemario: "Me refugia tu valva su envoltura caliente / la fisura en tu ovada estrechándome lenta / tus hebras encubriéndome en ondulada parda (...) / SOY LA SEMILLA OSCURA APENAS DELINEADA" (14).

\footnotetext{
Respecto al llamado y revelación de aquel otro mundo vinculado con los orígenes del hombre, Octavio Paz apunta: "Todos los días cruzamos la misma calle o el mismo jardín; todas las tardes nuestros ojos tropiezan con el mismo muro rojizo, hecho de ladrillo y tiempo urbano. De pronto, un día cualquiera, la calle da a otro mundo, el jardín acaba de nacer, el muro fatigado se cubre de signos. Nunca los habíamos visto y ahora nos asombra que sean así: tanto y tan abrumadoramente reales (...) No, esto que vemos por primera vez ya lo habíamos visto antes. En algún lugar, en el que acaso nunca hemos estado, ya estaban el muro, la calle, el jardín. Y a la extrañeza sucede la añoranza. Nos parece recordar y quisiéramos volver allá, a ese lugar en donde las cosas son siempre así, bañadas por una luz antiquísima y, al mismo tiempo, acabada de nacer. Nosotros también somos de allá. Un soplo nos golpea la frente. Estamos encantados, suspensos en medio de la tarde inmóvil. Adivinamos que somos de otro mundo. Es la 'vida anterior', que regresa” (133-134).
} 
En razón de tal encuentro, converge precisamente en la figura de la madre el carácter dual del sujeto, en tanto ella guarda en su propia unidad las marcas de un otro -el padre y el hijo-, constituye y se transforma en un otro, dando cuenta en sí misma de la naturaleza escindida de toda subjetividad, tal como propone Ricoeur (XIV). En este marco, plantea el autor, todo sujeto se dispone a partir de la dialéctica que se establece entre la identidad-idem y la identidad-ipse, entre el sí mismo y su otro, razón por la cual no es posible pensar al sujeto fuera de los dominios de esta alteridad (XIV). Para Ricoeur, el núcleo de la subjetividad es la ipseidad, en tanto esta solo puede ser percibida a través de una alteridad que es constitutiva del yo y a partir de la cual se posibilita la configuración de su identidad y la comprensión de esta como idem e ipse a la vez. Al no coincidir esta con los límites del sujeto respecto del mundo, dispuestos estos por el cogito cartesiano -y asociados, por tanto, al conocimiento objetivo y la experiencia sensible-, la alteridad se desprende del yo y trasciende tales lindes, disponiendo en conflicto su relación con la identidad-idem, entendida esta como la mismisidad, en oposición a lo variable, lo cambiante, lo inestable, propio de la ipseidad, la que no obstante está contenida en la anterior, según propone Ricouer:

Sí mismo como otro sugiere, en principio, que la ipseidad del sí mismo implica la alteridad en un grado tan íntimo que no se puede pensar en una sin la otra, que una pasa más bien por la otra, como se diría en el lenguaje hegeliano. $\mathrm{Al}$ «como», quisiéramos aplicarle la significación fuerte, no sólo de una comparación -sí mismo semejante a otro- sino de una implicación: sí mismo en cuanto... otro (XIV).

La identidad materna se encuentra ligada, por consiguiente, a esta alteridad en tanto la madre se configura como tal en razón de un otro, a partir del proceso de gestación y del parto, escisión esta última por medio de la cual se multiplica y diversifica ella en hijos y descendientes. En Fariña, el encuentro y reencuentro del sujeto consigo mismo y su origen da cuenta, por ende, de esta fisura: del quiebre y la articulación que ella misma implica entre el idem y el ipse, en los términos de Ricoeur (XIV); entre la función tética y el lenguaje poético, en Kristeva (El tema... 261); y entre el orden del significante y el sujeto de deseo, en el psicoanálisis lacaniano (Dor 131). Lo anterior, en función de la pugna y tensión permanente que se establece a lo largo de ambos poemarios entre un lenguaje poético en el que acontece la figura de un sujeto carente y descentrado, y el sistema hegemónico dominante, correspondiente al regimen dictatorial. En Fariña, se escinde entonces el 
sujeto de modo permanente, en tanto este solo logra reconocerse a sí mismo por medio de su propia alteridad, asomarse a través del velo que lo oculta, esto es el propio lenguaje que encubre y descubre al yo incansablemente, en conformidad con la naturaleza inherente del signo poético que lo configura -según los presupuestos de Kristeva (El tema... 258)-, y del sujeto, por ende, que subyace en los entramados de esta propia lengua:

\section{Amarillas}

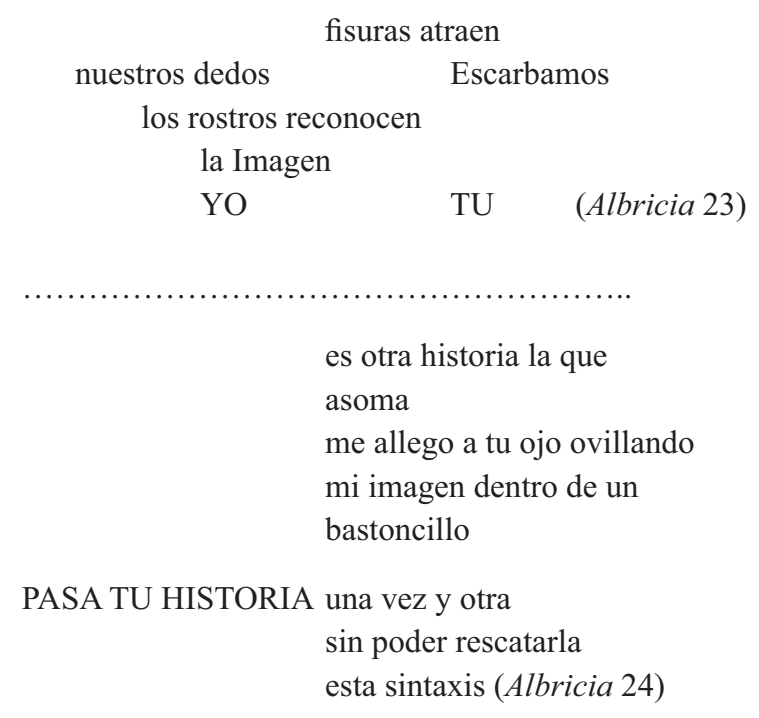

Aquel otro que asoma a través de la palabra -el sujeto, la madre, la verdad mítica- constituye, en consecuencia, aquel sujeto escurridizo, inasible, que emerge "sin poder rescatarla esta sintaxis" (Albricia 24) en tanto escapa a las amarras del verbo y, por ende, acontece sin que pueda reconocérsele con claridad. El sujeto constituye entonces un reflejo, la "Imagen" huidiza en la que el yo se espejea en su otredad, un yo inverso y oblicuo que se tuerce en el intento por acceder a sí mismo y a su identidad primigenia, tal como refiere la metáfora del espejo, vale decir, la mirada indirecta e inversa que posibilita el acceso a la verdad, a la sabiduría y al conocimiento humano (Chevalier 474-475).

Asimismo, la evocación a la figura de la madre por medio del intertexto mistraliano es evidenciada en Albricia mediante el epígrafe que abre la obra, correspondiente a una estrofa del poema La Cabalgata (52), perteneciente a 
Tala. Tal fragmento constituye, en el poemario de Fariña, la antesala o vía por medio de la cual se busca insertar esta escritura en el marco de la tradición poético-literaria chilena, particularmente femenina, y de una poética del hallazgo y la albricia, en la que tiene lugar la evocación del llamado como puerta de acceso al reino de la otredad, vale decir, de la verdad mítica, su búsqueda y espera: "Oír, oír, oír / la noche como valva, / ijar de lebrel / o vista acornejada / y temblar y ser fiel / esperando hasta el alba” (Mistral 52).

La presencia mistraliana en Fariña ${ }^{7}$ constituye, a su vez, un gesto que permite a esta poesía soslayar la censura de la época, en el contexto de una dictadura política que enalteció e idealizó la imagen de Gabriela Mistral como poetisa y maestra de escuela rural, amante de los niños, con vocación de madre abnegada, dedicada, vinculada a la fe católica. La imagen de Mistral fue, por consiguiente, aprehendida por el régimen totalitario y resignificada en pos de la construcción de una figura femenina congruente con los valores convencionales promulgados por la hegemonía política y conservadora, esto es, el de una mujer dócil, virtuosa, disciplinada, consagrada al bienestar y cuidado de sus hijos y familia, en el contexto de una sociedad eminentemente patriarcal. Liliana Trevizán alude, al respecto, al mito de la maternidad idealizado en la poesía de Mistral, a propósito de las canciones de cuna (120) y poemas vinculados al motivo de la reproducción femenina y la infancia publicados en Desolación, Tala y Lagar (122), asociaciones proyectadas finalmente hacia la imagen de la misma poeta, lectura esencialmente restrictiva que ha debido ser revertida en función de otras significativas connotaciones presentes en la escritura mistraliana ${ }^{8}$.

La referencia a Mistral en la obra de Fariña, específicamente a partir de Albricia -y la clara mención al título de este- ha sido atentamente revisada por la crítica: Ortega (192194), Olea (Albricia, un viaje... 35; Albricia... s/p), Merino (s/p), Bello (55-56), Grandón (218). En este marco, y a propósito de la producción poética femenina de los ochenta y de la investigación en torno a la premio Nobel, Bello señala: "Es en este contexto de 'emergencia nacional', durante la última década de la Dictadura, en que nuevos estudios sobre la obra de Gabriela Mistral y la eclosión de una escena de poesía escrita por mujeres -la de Fariña entre ellas- generan la noción, en un panorama lírico renovado, de una nueva crítica mistraliana, la que por primera vez permitió recuperar sentidos que habían sido omitidos o borrados en las apropiaciones de la primera mitad del siglo XX sobre la poeta, una tarea que al decir de Patricio Marchant se declara urgente e ineludible" (60).

El pensamiento político-social mistraliano y el análisis de la figura de la mujer desde los aportes de la crítica feminista constituyen aspectos que han sido abordados actualmente por la crítica literaria, en oposición a la imagen estereotipada de Mistral como mujer ejemplar 
En este sentido, la relación de filiación que establece la poesía de Fariña con la obra de Mistral constituye, por una parte, un recurso apropiado para enfrentar las políticas de censura implementadas por el gobierno militar y, por otra, un dispositivo de reposición del sujeto femenino en el marco de la escena literaria y artístico-cultural chilena de la época, en clara respuesta al patriarcado que desde sus inicios ha dominado el campo de la producción literaria nacional, latinoamericana y occidental ${ }^{9}$. La poesía de Fariña acontece entonces como heredera, hija de una tradición poética cuyo principal referente es femenino, legado al cual esta escritura busca a su vez sujetarse, como mecanismo o estrategia para dar consistencia y forma a un yo que, no obstante, se desfigura y desmorona indefectiblemente en el intento por sostenerse a sí

regida por los valores familiares, morales, republicanos y católicos, desde una perspectiva eminentemente patriarcal y conservadora. Los trabajos publicados por Olea y Fariña (eds.) (1990) y Rojo (1997) son clarificadores respecto a esta construcción restrictiva y distorsionada que monopolizó la figura de Mistral en el campo cultural y sociopolítico chileno hasta inicios de la década de 1990, y constituyen piedras angulares en el marco de las nuevas lecturas críticas en torno a la escritura mistraliana que comenzaron a levantarse a partir de esta fecha. Un antecedente de lo anterior, no obstante, constituye la carta que Enrique Lihn escribe a Mistral presumiblemente en 1981, en la que se plasma una mirada iluminada en torno a la poeta: "La lectura literal, pero atenta de tus mejores poemas -y no de tus páginas edificantessorprendería a más de algún creyente por el 'amor de la nada' que se trasluce en tus oraciones (...) en ese muro han abierto una hornacina y puesto, cada cual, una imagen inventada de su santa que se te parece, pero no más que un mármol a un cuerpo y tanto como una figura a una sombra" (Lihn 524).

9 Tal como anuncia Bello (60), durante los años ochenta la escritura femenina chilena fue adquiriendo paulatinamente realce en nuestro país, alcanzando hacia fines de la década un espacio significativo tanto en el marco de la producción poética nacional como en el de la crítica literaria. Soledad Fariña forma parte de este movimiento del que ella misma da cuenta en su artículo Inicios de la Crítica Literaria Feminista en Chile, en el cual se expone que, a raíz de algunas jornadas internacionales -entre ellas el II Encuentro Feminista de América Latina y el Caribe (Lima, 1983) y el I Congreso Internacional de Literatura Femenina Latinoamericana (Santiago de Chile, 1987)-, y ciertos movimientos y manifestaciones que comenzaron a tener lugar al interior del país en oposición al régimen militar, comienza poco a poco a levantarse tanto en el ámbito de la lucha política como en el de la producción artístico-cultural, una nueva comprensión de las mujeres como "sujetos activos" (48). Es así como en el contexto de una escena cultural nacional, heredera de una tradición fundamentalmente patriarcal, el congreso realizado en nuestro país en 1987 fue especialmente significativo en la apertura y valoración de un espacio para el trabajo crítico-literario desarrollado por mujeres. En esta línea, los estudios críticos de Eliana Ortega, Nelly Richard, Soledad Bianchi, Raquel Olea y de las poetas Soledad Fariña, Eugenia Brito y Elvira Hernández, entre otras, alcanzan una mayor tribuna en el campo literario chileno de la década. 
mismo como también por transfigurarse y ocultarse a través de la palabra para no ser reconocido por el sistema opresor. El gesto, en Fariña, constituye en consecuencia un ejercicio de enmascaramiento del sujeto fallido y carente, quien se encubre bajo la referencia mistraliana cual hija pequeña se esconde tras las faldas de su madre, en tanto aquella solo puede evidenciarse a través de su propia alteridad y viceversa, dimensión permanentemente escudriñada por el yo: "desde la esfera hueca / desciende / hasta tu lengua / buscando la cadencia" (Albricia 30), "Palpando tu resuello / busco mi raíz / en el bombeo azul de tu garganta" (Albricia 31).

El intento por dar lugar a la "conversión de las mujeres en sujeto", en palabras de Kirkwood (209), por medio de la evocación de una voz femenina validada y legitimada en el marco de la tradición poética chilena, constituye el gesto filial en Fariña en el que tiene lugar, no obstante, la ejecución de una fisura subrepticia, de una fractura mediante la cual se busca desestabilizar el orden del lenguaje -la conciencia tética-y, por consiguiente, la estructura logocéntrica que rige el discurso hegemónico, en pos de la recuperación y retorno a los tiempos de los orígenes y la infancia. Lo anterior, en función a su vez del carácter transgresor que, en rigor, el mismo pensamiento mistraliano constituye en términos ideológicos y sociopolíticos ${ }^{10}$, lo que da cuenta, en consecuencia, de la figura de una Mistral en cuanto referente usurpado, deformado por el régimen dictatorial, periodo bajo el cual se enfatizaron en torno a ella valores hegemónicos y patrios (Pizarro 99) que ya la anquilosada crítica literaria había referido -y edificado- décadas atrás.

Asimismo, a partir de las referencias antropológicas a través de las cuales se configura la noción de sujeto en Fariña y en el marco de las filiaciones que esta escritura busca establecer con sus antepasados poéticos en el contexto de la tradición literaria chilena, se reconocen en ambos poemarios claves que se entroncan con la poética del lar promulgada por Jorge Teillier a mediados de la década del sesenta (21), ello en razón de la evocación de los tiempos primordiales asociados a la dimensión del mito y de la recuperación de la

10 Actualmente, el análisis del pensamiento social de Gabriela Mistral constituye un aspecto clave en los estudios que se han desarrollado en torno a su obra, en los cuales se destaca la preocupación y reflexión crítico-ideológica de la autora en torno a temas y problemáticas vinculadas al mundo indígena, el mestizaje, la tierra e identidad latinoamericana, la mujer, la patria, el campesinado, las políticas públicas y los derechos sociales. En este marco, citamos los trabajos de Olea y Fariña (1990), Rojo (1997), Figueroa, Silva y Vargas (2000), Falabella (2003), Falabella y Domange (2010) y Morales (2011). 
infancia y el paraíso perdido. En esta línea, el deseo del sujeto por retornar al origen y acceder al encuentro consigo mismo y con sus antecesores, en el marco de una "poesía genealógica" (23), constituye un aspecto central en la poética teillieriana, en función de los antepasados que acompañan al poeta y de su presencia constante en el universo poético que este evoca, lo que se vincula estrechamente a la preocupación por el rescate de los valores más humanos y profundos -valores poéticos- provenientes de los tiempos inmemoriales relativos a la gestación del mundo y del hombre, en tanto estas figuras ancestrales - los abuelos, el padre, la madre- configuran entidades míticas, dado que en ellas se condensa la reminiscencia de una época ligada a los orígenes, a la fundación de los pueblos. La infancia, precisamente, se plantea como una de las dimensiones con las cuales se corresponde el universo mítico en razón de la edad de oro teillieriana, asociada esta a los tiempos primordiales, las primeras edades del hombre y de los pueblos y, en consecuencia, al paraíso perdido que es necesario recuperar con el fin de acceder a la verdad sagrada -poética- en torno a nosotros mismos: "la infancia es un estado que debemos alcanzar, una recreación de los sentidos para recibir limpiamente las maravillas del mundo" (63), señala Teillier al respecto.

En Fariña, la evocación a los antepasados determinada por la figura de la madre y el retorno a los dominios de la infancia constituyen, en este sentido, vías por medio de las cuales el sujeto busca acceder a la recuperación de sí mismo, en su estadio inaugural y primigenio, lo que acontece en el espacio uterino, en el dominio de la otredad materna de la que el yo ha sido separado -desgarrado- en el instante del parto y a la cual irremediablemente desea retornar. Tal como propone Octavio Paz, el hombre "se realiza o cumple cuando se hace otro. Al hacerse otro se recobra, reconquista su ser original, anterior a la caída o despeño en el mundo, anterior a la escisión en yo y "otro"” (180).

Adriasola señala, al respecto, que la alusión a "ALFA" - primer grafema del sistema griego- en los versos finales de El Primer Libro, representa la referencia al principio (7), a los albores de la humanidad, el inicio de los tiempos y del lenguaje; es, en este sentido, evocación al lenguaje infantil en razón de las primeras edades de hombre. El término "ALFA" que en el poema se desarma y transforma en "Alfalfa", "Falfa" (55), "Fabla" (57), cual balbuceo de un niño al comenzar a adquirir la palabra, constituye por consiguiente el signo de la primera edad que se busca recobrar, la vuelta al origen a través de la pérdida y el desmoronamiento del verbo, como también, la recuperación y reconstitución del mismo en función de las reminiscencias etimológicas 
respecto de las cuales, a su vez, la lengua va y vuelve constantemente: alfa y fabla. La palabra, al igual que el yo, se configura por consiguiente en la tensión de un movimiento pendular y permanente, hacia atrás y hacia delante, hacia el origen y el presente, hacia el mito y el logos, en tanto ella es la materia misma del cuerpo del sujeto. En este oscilar, las referencias centradas en las raíces de la lengua española correspondientes al griego y latín constituyen, del mismo modo, los primeros intentos de enunciación mediante los cuales busca configurarse paulatinamente el yo, en pos de otorgarse a sí mismo forma y dignidad por medio de la palabra, cual investidura o ropaje que le devela y encubre a la vez. El lenguaje sujeta, en consecuencia, al yo, y lo somete al dictamen o mandato decretado por la fuerza hegemónica asociada a la tradición y la cultura: "HABLA (...) HABLA" (33), concluyen los versos en El Primer Libro. Es, por una parte, la voz del opresor que acoge al sujeto en tanto lo recoge o "dobla" (33), lo tuerce y transfigura en otro; y, por otra, desde el otro extremo del péndulo, la voz de la madre quien recibe al hijo al momento de dar a luz, instante en el que se profiere la palabra materna cual ofrenda o aliento que otorga vida al yo, el legado ancestral -sagrado-que se entrega al hijo mortal y que consiste en su única herramienta o instrumento de sobrevivencia.

Los versos de la última sección en El Primer Libro finalizan, por consiguiente, en el instante en que se inicia el proceso de adquisición de la palabra por parte del yo, en vías de la configuración o conformación del mismo como sujeto, estadio al que, sin embargo, no se logra acceder completamente en tanto el yo poético constituye un "sujeto en proceso" (Kristeva, El tema... 262), en razón de la tensión a la cual es sometido y relegado permanentemente por parte del sistema verbo-simbólico. Los versos finales "HABLA / -le digo / (se dobla) / HABLA" (33), con los cuales cierra el poemario, dan cuenta en síntesis de este balbuceo inicial y el silencio posterior -y simultáneo- que rodea la emisión de las últimas palabras del texto, de modo previo al acto de emergencia o aparición inminente -suspendida y final- de un sujeto trunco, escindido y malformado, en función de la pugna permanente que constituyen en sí mismos los procesos de gestación y nacimiento, ambos constitutivos de un solo acto doloroso de enfrentamiento, transmutación y engaño del yo $-\mathrm{y}$ viceversa- frente a la fuerza dictatorial y hegemónica: 
$(\ldots)$

$\begin{array}{lll} & \text { La tibia } & \text {-dice } \\ \text { Fabla } & & \text {-me dice } \\ \text { Fabla } & \begin{array}{l}\text { mi tierno dulce } \\ \text { mi amarga suave }\end{array} & \\ & & \end{array}$

abre la cuenca

escarba

brota

la cuenca huesa

la blanca suelta

la suave

\section{DOBLA}

HABLA

-le digo

(se dobla)

HABLA (33)

\section{HALLAZGO ILUSORIO DEL SUJETO POÉTICO}

La doble funcionalidad del lenguaje en la constitución del yo, primero, como mecanismo de represión en tanto anclaje de la conciencia tética y el orden simbólico-cultural, y segundo, como única materialidad capaz de dar forma a la entidad subjetiva -parcial y en apariencia-, constituye finalmente la arcilla movediza a partir de la cual emerge el sujeto en balbuceo, signado por una enunciación que, en consecuencia, se vuelve incierta, débil y esquiva. El lenguaje en Fariña constituye, de este modo, la trampa por medio de la cual se pretende materializar un proyecto que no es otra cosa que ilusión, apariencia, desdoblamiento. El sujeto en Fariña "se dobla", se tuerce, se escurre, a la vez que intenta mascullar el verbo, aprehenderlo, y es, precisamente, en este fraccionamiento, en esta escisión, en donde se alcanza y se pierde, aparece y desaparece, adviene y se ausenta en el eclipse del lenguaje como arguye la teoría lacaniana (Dor 123). Al yo no le es posible, entonces, erigirse como una entidad íntegra, completa, uniforme en tanto su propia naturaleza, dada desde su gestación, la concibe como una figura "apenas delineada" (Albricia 33 ), borrosa, fragmentada, fallida. Su propia materialidad fundada en el 
lenguaje escindido da cuenta, por ende, de la imposibilidad del hallazgo o de la posibilidad de un hallazgo que es, en definitiva, ilusorio - mera representación-, pues para su cumplimiento la palabra requiere necesariamente del silencio a partir del cual el sujeto emerge, no obstante, como entidad soluble y ausente.

El silencio constituye, en este sentido, el dominio a través del cual se oculta y resguarda la albricia, el conocimiento mítico, aquel misterio o secreto que guarda la palabra poética y que se transforma en "secreción" (Block de Behar 213-214), en un excedente sin forma que surge a partir de la convergencia entre el entramado verbal y aquello que no se dice, aquello que se ubica en el "borde del lenguaje" (Paz 147): zona límite -entre el verbo y su ausencia-en la cual precisamente "ocurre la literatura" (Block de Behar 215). El silencio es concebido, por ende, como aquella alteridad que se despliega a partir del texto y que lo trasciende (216) en conformidad a su propia naturaleza, por tanto, no se muestra, no se deja asir completamente. En Fariña, tal alteridad la constituye en efecto el sujeto al cual se busca "pintar" y moldear, otorgar un cuerpo que es provisto finalmente por la lengua, la que desde su doblez y contorsión se dispone como único mecanismo mediante el cual el yo puede erguirse -y desmoronarse a la vez-, en tanto es ungido de forma y aliento para hacer frente a la entidad opresora:

Había que pintar el primero libro pero cuál pintar
cuál primer tomar todos los ocres también
el amarillo oscuro de la tierra
capas unas sobre otras: arcilla terracota ocre
arañar un poco lamer los dedos para formar
una pasta ligosa
untar los dedos los brazos ya estás abierto
páginas blancas abiertas no hay recorrido previo
tratar de hendir los dedos (23)

Tal movimiento, no obstante, se ejecuta desde la torcedura, a partir del gesto dislocado por el mismo lenguaje que transforma al sujeto en un corpus malogrado, descentrado y escindido, en consecuencia, inasible, imposibilitado para asistir a su propio encuentro, en el hallazgo ilusorio que se (des)perfila desde su gestación. En su propia Arte Poética (Cit. en Calderón, Calderón y Harris 232), Fariña alude precisamente a la imposibilidad de aprehensión del sujeto y, por consiguiente, del fenómeno mítico-poético que constituye él mismo, aquello que se encuentra y se pierde a la vez en el lenguaje: 


\author{
y ver \\ que apenas dibujada en el aire \\ el aire se encabrita y sale a buscar paisajes \\ otros imposibles de deletrear
}

Caer en la oscuridad informe de su semilla

y volver a trazarla en la ilusión

de su sonrisa oblicua

(...)

Sumergirla

vestirla con el vértigo

de no poder nombrarla (232)

En consecuencia, en su condición de sujeto poético, el yo emerge e intenta tomar forma por medio de su materia verbal, no obstante, es este mismo cuerpo y tejido el que interfiere e impide la materialización del encuentro. Si bien el único recorrido que permite el acceso al sujeto es la palabra, su imposibilidad de nominación finalmente prevalece, debido a su carácter huidizo y difuso, inaprehensible, condición que le relega finalmente a la naturaleza del afuera referida por Foucault, la que "no puede ofrecerse como una entidad positiva (...) sino únicamente como la ausencia que se retira lo más lejos posible de sí misma y se abisma en la señal que emite para que se avance hacia ella, como si fuera posible alcanzarla" (El pensamiento... 34). Bajo dicho signo y circunstancia, determinados por el orden de la lengua, la cultura y el régimen militar, el yo en Fariña constituye, en definitiva, una entidad informe, imprecisa y contrahecha en tanto no consigue acontecer completamente por medio de la palabra, sino por el contrario, esta solo permite vislumbrar los retazos de una figura maltrecha, un sujeto a medias, una especie de quasimodo a quien no le es posible revelar su verdadero rostro.

BIBLIOGRAFÍA

Adriasola, María Teresa. "Lo Sagrado del Primer Libro: el libro de la creación”. Revista Lar (1987): 7-10.

Anónimo. Popol-Vuho el Libro del Consejo de los Indios Quichés. Buenos Aires: Losada, 1996.

Barraza Riso, Ángela. 'El Primer Libro' de Soledad Fariña. Entrevista. Revista LDDS, 2011.

Recuperado de: http://www.letras.s5.com/aba120112.html. 
Bellesi, Diana. "La Vocal de la Tierra. Tres poemas de Soledad Fariña". Cyber Humanitatis 16 (2000). Recuperado de: http://www2.cyberhumanitatis.uchile.cl/16/escritoras2b.html.

Bello, Javier. "Hacia una poética de Soledad Fariña. Prototexto y escritura cifrada en 'La Vocal de la Tierra"'. Revista Chilena de Literatura 75 (2009): 47-67.

Biblia Latinoamericana. Madrid: Ediciones Paulinas, Editorial Verbo Divino, 1972.

Block de Behar, Lisa. Una retórica del silencio. Funciones de lector y procedimientos de la lectura literaria. México: Siglo XXI, 1984.

Brito, Eugenia. Campos Minados (Literatura Post-golpe en Chile). Santiago: Cuarto Propio, 1994.

Calderón, Teresa, Lila Calderón y Tomás Harris. Veinticinco Años de Poesía Chilena (19791995). Santiago: Fondo de Cultura Económica, 1999.

Chevalier, Jean. Diccionario de Símbolos. Barcelona: Herder, 1986.

Dor, Joël, Introducción a la Lectura de Lacan I. El inconsciente estructurado como lenguaje. Barcelona: Gedisa, 1997.

Eliade, Mircea. Historias de las creencias y de las ideas religiosas. IV. Las religiones en sus textos. Madrid: Ediciones Cristiandad, 1980

Mito y realidad. Barcelona: Kairós, 2006.

Falabella Luco, Soledad. ¿Qué será de Chile en el cielo? 'Poema de Chile’ de Gabriela Mistral. Santiago: LOM Ediciones, 2003.

Falabella Luco, Soledad y Bernardita Domange. "'Poema de Chile', sus manuscritos y la valoración del legado de Gabriela Mistral”. Estudios Filológicos 46 (2010): 43-57.

Fariña, Soledad. El Primer Libro. Santiago: Ediciones Amaranto, 1985.

Albricia. Santiago: Ediciones Archivo, 1988.

“Sabio". Entrevista en torno a Juan Luis Martínez (documento audiovisual), 2003.

Recuperado de: http://juanluismartinez.cl/jlm/sobre-la-obra/entrevistas/.

"Inicios de la Crítica Feminista en Chile". Mapocho 55 (2004): 45-60.

Figueroa, Lorena, Keiko Silva y Patricia Vargas. Tierra, indio, mujer: pensamiento social de Gabriela Mistral. Santiago: LOM Ediciones, 2000.

Foucault, Michel. Estética, ética y hermenéutica. Obras esenciales. Volumen III. Barcelona: Ediciones Paidós, 1999.

El pensamiento de afuera. Valencia: Pre-textos, 2004.

Gadamer, Hans-Georg. Verdad y Método II. Salamanca: Ediciones Sígueme, 1992.

Mito y razón. Barcelona: Paidós, 1997.

Grandón Laguna, Olga. "Revaloración del mundo primigenio en la poesía de Soledad Fariña". Literatura y Lingüística 33 (2016): 217-238.

Jameson, Fredric. Ensayos sobre el posmodernismo. Buenos Aires: Imagino Mundi, 1991.

Kirkwood, Julieta. Ser política en Chile. Las feministas y los partidos. Santiago: FLACSO, 1986.

Kristeva, Julia. "El tema en cuestión: el lenguaje poético". La identidad. Claude Lévi-Strauss.

Barcelona: Ediciones Petrel, 1981.

El poder de la perversión. Ensayo sobre Louis-Ferdinand Céline. México: Siglo XXI, 2006. 
Lacan, Jacques. El Seminario de Jacques Lacan. Libro 11. Los cuatro conceptos fundamentales del psicoanálisis. Buenos Aires: Paidós, 1987.

Escritos I. México: Siglo XXI, 2009.

Lihn, Enrique. El circo en llamas. Santiago: LOM Ediciones, 1997.

Merino, Roberto. “'Albricia' de Soledad Fariña. El viaje de la lengua por los cuerpos”. APSI, 295 (1989). Recuperado de: http://letras.s5.com/sfar120214.html.

Mistral, Gabriela. Tala. Buenos Aires: Ediciones Sur, 1938.

Morales, Leonidas. "Gabriela Mistral: Recados de la aldea". Revista Chilena de Literatura 80 (2011): 203-222.

Olea, Raquel. “Albricia, un viaje hacia la lengua”. Número Quebrado 2 (1989): 35. Recuperado de: http://letras.s5.com/sf050411.html.

"Prólogo". El Primer Libro. Soledad Fariña. 2 edición. Buenos Aires: Libros de Tierra Firme, 1991.

Producciones de lo femenino en la escritura de mujeres chilenas. Santiago: Cuarto Propio, 1998.

“Albricia”. Texto de presentación a la reedición de 'Albricia' de Soledad Fariña. Editorial Cuneta, 2010. Recuperado de: http://letras.s5.com/sf280710.html.

Olea, Raquel y Soledad Fariña. Ed. Una palabra cómplice: Encuentro con Gabriela Mistral. Santiago: Cuarto Propio, 2da edición, 1997.

Olea, Raquel. "Deseo y signo de otra escritura. La poesía de Soledad Fariña”. Lengua Víbora. Producciones de lo femenino en la escritura de mujeres chilenas. Santiago: Cuarto Propio. Corporación de Desarrollo de la Mujer La Morada, 1 era. edición, 1998.

Ortega, Eliana. Lo que se hereda no se hurta. Ensayos de crítica literaria feminista. Santiago: Cuarto Propio, 1996.

Oyarzún, Kemy. "Teoría crítica, feminismo y crisis del sujeto". Identidades y Sujetos. Para una discusión latinoamericana. Ed. José Luis Martínez. Santiago: LOM Ediciones, 2002.

Oyarzún, Pablo. "Palabra incorporada". Presentación de 'La Vocal de la Tierra de Soledad' Fariña, 2012. Recuperado de: http://letras.s5.com/sfa261112.htm.

Paz, Octavio. El arco y la lira. México: Fondo de Cultura Económica, 1996.

Pizarro, Ana. "Gabriela Mistral en el discurso cultural". Una palabra cómplice: Encuentro con Gabriela Mistral. Ed. Raquel Olea y Soledad Fariña. Santiago: Cuarto Propio, 2da edición, 1997.

Ricoeur, Paul. Sí mismo como otro. México: Siglo XXI, 2003.

Rojo, Grínor. Dirán que está en la gloria ... (Mistral). Santiago: Fondo de Cultura Económica, 1997.

Teillier, Jorge. Prosas. Santiago: Editorial Sudamericana, 1999.

Trevizán, Liliana. "Deshilando el mito de la maternidad". Una palabra cómplice: Encuentro con Gabriela Mistral. Ed. Raquel Olea y Soledad Fariña. Santiago: Cuarto Propio, 2da edición, 1997. 